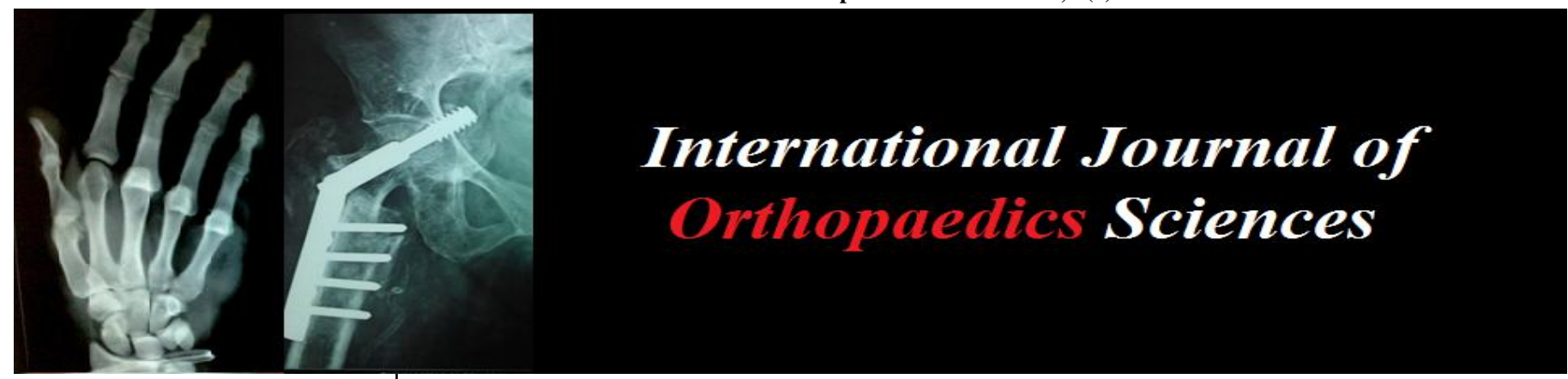

ISSN: $2395-1958$

IJOS 2019; 5(2): 642-645

(C) 2019 IJOS

www.orthopaper.com

Received: 17-02-2019

Accepted: 21-03-2019

Dr. Kapil Bansal

Assoct. Prof, Dept. of orthopaedics GGSMCH

Faridkot, Punjab, India

Dr. Anshul Dahuja

Assistant Professor,

Dept. of orthopaedics GGS

Faridkot, Punjab, India

Dr. Rashmeet Kaur

Assistant Professor,

Dept. of Radiodiagnosis

GGSMCH Faridkot, Punjab,

India

Dr. Jagdeep Singh

Assoct. Prof, Dept. of

Orthopaedics GGS Faridkot,

Punjab, India

Dr. Radhe Shyam

Prof. and head of Dept. of

orthopaedics GGSMCH

Faridkot, Punjab, India
Correspondence

Dr. Anshul Dahuja

Assistant Professor,

Dept. of orthopaedics GGS

Faridkot, Punjab, India

\section{Proximal femur nail vs cemented bipolar prosthesis in unstable intertrochanteric femur fractures in elderly: A prospective study}

\author{
Dr. Kapil Bansal, Dr. Anshul Dahuja, Dr. Rashmeet Kaur, Dr. Jagdeep \\ Singh and Dr. Radhe Shyam
}

DOI: https://doi.org/10.22271/ortho.2019.v5.i2i.65

\begin{abstract}
Background: Surgical stabilization of Intertrochanteric fracture femur is one of the most commonly performed orthopaedic procedures. Present study was done to analyse the outcome of various treatment modalities for unstable Intertrochanteric fracture femur in elderly.

Methods: The present clinical study was carried out at our tertiary care hospital. Study duration was from Jan 2015 to June 2016. 70 patients over the age of 60 years with unstable Intertrochanteric fracture were selected. Outcome of management of unstable Intertrochanteric fracture femur was analysed using Harris Hip Score in Proximal femoral nail (PFN) and Cemented Bipolar prosthesis (CBP).

Results: Most of the patients were between 60-70 years of age. The average age of study group was 68.9 years. 35 patients treated with PFN and 35 patients treated with CBP. Superficial infection was seen in 4 patients and was the most common complication found in cemented bipolar prosthesis. External rotation deformity was second most common complication seen in 5 patients. Out of them, 2 patients were of CBP and 3 patients of PFN. Deep wound infection occurred in 1 case of CBP. Average blood loss in patients operated with PFN and CBP were $205 \mathrm{ml}$ and $311 \mathrm{ml}$ in CBP. It was noted that shorter time was required for P.F.N (55 $\mathrm{min}$ ) and then for CBP (84min). Average Harris score for PFN and CBP at 3 months, at 1 year and at 2 years were 70.1:74.9, 86.4:78.2 and 84.4:76.6.

Conclusion: Considering the amount of blood loss, duration of the surgery and Harris Hip Score, PFN is better for unstable inter trochanteric fracture femur than CBP. The only advantage of Hemiarthroplasty was early weight bearing. But at the end of 1 year and 2 years, the outcome of PFN was better than Cemented Bipolar prostheses.

Statistical method: Data were reported as mean, median (range) or number. t-test was used to assess significant difference among all numerical parameters of the study within the two surgical groups. $\mathrm{P}-$ values $<0.05$ were considered statistically significant.
\end{abstract}

Keywords: Harris hip score, Proximal femoral nail, Bipolar prosthesis.

\section{Introduction}

Elderly patients with hip fractures constitute the Largest Group of Emergency Orthopaedics Admissions ${ }^{[1]}$. With an expected incidence of 6.26 million by the year 2050, an increase in these fractures is on the rise due to the increased life expectancy of the people and osteoporosis [1-4].

It is universally agreed that the treatment of Intertrochanteric fractures is stable fixation as early as possible. Stable fixation is the keystone of successful union of trochanteric fractures. Surgical stabilization of Intertrochanteric fracture femur is one of the most commonly performed orthopaedic procedures.

Four major categories of operative treatment can be distinguished, including nail plates and blade plates with a fixed angle, sliding screws and plate devices, rigid intra medullary devices, flexible intra medullary devices and arthroplasty. Each method has recognized advantages and disadvantages. Some studies reported that hip arthroplasty could shorten the weight bearing time, reduce the incidence of implant-related complications and improve the hip function when compared with internal fixations by Gamma nails, dynamic hip screws, and proximal femoral nails $(\mathrm{PFN})^{[3,4]}$. Contrarily recent studies indicated that proximal femoral nail (PFN) currently 
is an optimal implant for the treatment of different type of intertrochanteric fractures ${ }^{[5-8]}$. So far, however, there is only one prospective randomized study comparing PFN with hemiarthroplasty for senile intertrochanteric fractures in the literature ${ }^{[4]}$. Present study is done to analyse the outcome of PFN (proximal femur nail) with CBP (Cemented Bipolar) for treating unstable Intertrochanteric fracture femur in elderly.

\section{Material and methods}

The prospective study was conducted in a tertiary institute by collecting data of 92 cases of unstable and complex intertrochanteric fracture who have undergone proximal femur nail and cemented hemiarthroplasty, selected through prior randomization based on a computer based random number sequence by a person uninvolved in the surgical procedure from Jan 2015 to Feb 2016 with 2 years follow up. Surgically fit post-traumatic patients more than 60 years of age who has been diagnosed as having complex/unstable intertrochanteric fractures which include posteromedial large separate fragmentation, basicervical patterns, reverse obliquity, displaced greater trochanteric fractures and failure to reduce fracture before fixation or with sub-trochanteric extension were included in study. Patients with following conditions were excluded, patients who had less than 6 months of follow-up, bilateral fractures, pathological or compound fractures, fractures associated with polytrauma, pre-existing femoral deformity preventing hip screw osteosynthesis or intra-medullary nailing and subtrochanteric fractures, fractures extending $5 \mathrm{~cm}$ distal to the inferior border of the lesser trochanter.

Clinical Outcome of management of unstable Intertrochanteric fracture femur by using Proximal femoral nail (PFN) and Cemented Bipolar prosthesis (CBP) was analysed with Harris hip score ${ }^{9}$. Partial weight bearing was allowed within a week onwards with the assistance of a walker. Mean follow up period was 22.5 months (18-31 months).
Statistical analysis: The continuous variables were declared as mean \pm standard deviation (SD). Depending on the distribution, mean values were compared using student $t$ test. Statistical significance was determined with $\mathrm{P}<.05$.

ERB (ethical review Board approval has been taken)

Conflicts of interest: none.

\section{Results}

Most of the patients were between 60-70 years of age. The average age of study group was 68.9 years. 52 patients treated with PFN and 40 patients treated with CBP. Average blood loss in patients operated with PFN and CBP were $185 \mathrm{ml}$ and $311 \mathrm{ml}$ in CBP. It was noted that shorter time was required for P.F.N (55 min) and then for CBP (84min) shown in table no.1. Superficial infection was seen in 5 patients with a ratio 3:2 in CBP: PFN respectively. Deep wound infection occurred in 2 cases of CBP and 1 case in PFN group (table no.2). Average Harris hip score for PFN and CBP at 3 months, at 1 year and at 2 years were 74.9:67.1, 79.2:84.2 and 76.6:83.8 (table no.3).

Table 1: Demographic and Intraoperative data

\begin{tabular}{|c|c|c|c|c|}
\hline s.no. & & $\begin{array}{c}\text { CBP } \\
\text { Group }\end{array}$ & $\begin{array}{c}\text { PFN } \\
\text { Group }\end{array}$ & $\begin{array}{c}\text { P } \\
\text { value }\end{array}$ \\
\hline 1 & No. of patients & 40 & 52 & - \\
\hline 2. & Male: female & $25: 15$ & $33: 19$ & - \\
\hline \multirow{2}{*}{3.} & AO type & & & - \\
\cline { 2 - 3 } & $31 \mathrm{~A} 2.2$ & 12 & & \\
\cline { 2 - 3 } & $31 \mathrm{~A} 2.3$ & 17 & & \\
\hline 4. & $31 \mathrm{~A} 3.3$ & 11 & & - \\
\hline 5 & Singhs index <=3:>3 & $31: 9$ & $35: 17$ & $<0.001$ \\
\hline 6. & Av. Blood loss & $185 \mathrm{ml}$ & $311 \mathrm{ml}$ & $<0.001$ \\
\hline 7. & $\begin{array}{c}\text { Blood } \text { Surgery time } \\
\text { units) }\end{array}$ & $55 \mathrm{~min}$ & $84 \mathrm{~min}$ & $<0.05$ \\
\hline 8. & Postop Hb & 36 units & 9 units & $<0.033$ \\
\hline 9. & Cementing reaction & 2 & 9.6 & - \\
\hline
\end{tabular}

Table 2: Postoperative outcomes in CBP and PFN Group

\begin{tabular}{|c|c|c|c|c|}
\hline S.no & Complication & CBPgp(40) & PFN gp(52) & P value \\
\hline 1 & Mortality rate within 2 years & 4 & 1 & $<0.05$ \\
\hline 2 & Dislocation & 2 & 0 & - \\
\hline 3 & Limb Length Alteration & 3 & 4 & $>0.99$ \\
\hline 4 & Deep Vein Thrombosis & 1 & 1 & $>0.99$ \\
\hline 5 & Pulmonary infection & 4 & 1 & $<0.05$ \\
\hline 6 & Prosthetic/implant related & 2 & 1 & 0.79 \\
\hline 7 & Superficial Infection & 3 & 2 & 0.067 \\
\hline 8 & Deep infection & 2 & 1 & 0.81 \\
\hline 9. & Average hospital stay & 14 & 10 & $<0.05$ \\
\hline 10. & Av.Partial weight bearing & $5^{\text {th }}$ day & $9^{\text {th }}$ day & $<0.05$ \\
\hline 11. & Revision surgery & 2 & 1 & $>0.99$ \\
\hline
\end{tabular}

Table 3: Functional outcomes in CBP and PFN Group

\begin{tabular}{|c|c|c|c|}
\hline (n=52) & CBP Group (n=40) & PFN Group & P value \\
\hline Follow-up Period in months (range) & $23(18-29)$ & $25(19-32)$ & - \\
\hline Mean Time to full weight bearing (weeks) & 3 weeks & 8.2 weeks & $\mathrm{p}<0.001$ \\
\hline Harris Hip Score (100) & & & \\
\hline 3 months & 74.9 & 67.1 & $\mathrm{p}<0.001$ \\
\hline 12 months & 79.2 & 84.2 & $\mathrm{p}<0.05$ \\
\hline 24months & 76.6 & 83.8 & $\mathrm{p}<0.01$ \\
\hline Radiological union (mean duration) & - & 5.5 months & - \\
\hline
\end{tabular}

\section{Discussion}

Hemiarthroplasty is always one of the choice in unstable intertrochanteric femoral fractures ${ }^{[5]}$. Some studies reported that hip arthroplasty in treating these fractures had more advantages than internal fixations [4, 10-13]. However, the findings of the present study did not support hemiarthroplasty as a preferred choice when compared with PFN. Although hemiarthroplasty is a preferable alternative, intramedullary 
fixation techniques, which need less surgical cut, have been developed to protect patient's bone structure. Proximal femoral nail is the internal fixation technique that causes minimum bone loss in femoral head and femoral neck ${ }^{[6]}$.

Tang et al. reported that at 3 years follow-up, there was no significant difference in Harris Hip Score between PFNA and hemiarthroplasty group $(83.0 \pm 12.2$ for the PFNA group and 80.2.1 \pm 10.9 for the hemiarthroplasty group, $P=0.09)^{[14]}$. Ozkayin $\mathrm{N}$ et al. conducted a prospective randomized study comparing PFN with hemiarthroplasty for intertrochanteric fractures in the elderly, and found that at 3 months, Harris Hip Score average was 45.24 in PFN group and 63.38 in hemiarthroplasty group respectively, with significant difference; while at 12 months, Harris Hip Score average was 75.95 in PFN group and 68.44 in hemiarthroplasty group respectively, with significant difference ${ }^{[4]}$. In the present study, at 1 and 2 year follow-up, there is statistically difference between the two groups regarding to the Harris Hip Score. Our results also strengthened by Shen $\mathrm{J}$ et al. categorically stated after studying 124 patients above 70 years of age, that Internal fixation is preferred as it leads to a higher Harris scores, lesser pain, and better walking ability than those treated with hemiarthroplasty provided there is good and stable reduction, even when severe osteoporosis is present ${ }^{[15]}$. Tang $\mathrm{P}$ et al, after retrospectively studying 303 patients concluded that PFNA was superior to hemiarthroplasty according to the operative statistics, especially the anaesthesia, operation lasting time, blood loss, blood transfusion and the drainage and our study found similar results ${ }^{[14]}$.

As Pho RW et al. and Siwach R et al. reported that only 75$88 \%$ of patients treated with hemiarthroplasty could successfully ambulate and our study found similar results probably because of more postoperative complications in cemented bipolar group ${ }^{[16,17]}$.

Although many studies indicated that hemiarthroplasty in treating these fractures had very low incidence of postoperative complications but the issues of hemiarthroplasty, such as prosthetic dislocation, prosthesis loosen and cement reaction, cannot be completely avoided, which are mainly depended on the skill level of the operating surgeon ${ }^{[3,10,11,18,19]}$. Tang et al. showed no difference in the functional results but the incidence of complications was higher in hemiarthroplasty group than in PFN group $(14.1 \%$ vs. PFN $8.96 \%$ ), with no statistics difference ${ }^{[14]}$. In our study, we had two cases of postoperative hip dislocation and two cases of intraoperative cement reaction in CBP group. Superficial and deep infections were statistically similar in both the groups.

The procedures of hemiarthroplasty in treating intertrochanteric fracture are much more complicated than in treating femoral neck fracture, especially in case of comminuted intertrochanteric fractures. PFN had been approved to be an effective method in treating unstable senile intertrochanteric fractures with low rates of internal fixation failure and related reoperation ${ }^{[20,21]}$. Present study, we found a trend of higher 2 year mortality for patients who underwent primary hemiarthroplasty compared with those underwent PFN (10\% vs. $2 \%$ ) strengthening the previous results obtained by Tang et al. ${ }^{[14]}$. One potential reason of leading to higher mortality in patients treated with hemiarthroplasty was the relative greater surgical trauma that hemiarthroplasty brought to the aging patients along with higher pulmonary infection rate postoperatively.

The treatment of unstable IT fractures needs meticulous preoperative planning, good intra-operative reduction and use of intra-medullary implants. The surgeon is free to use any design amongst the many intra-medullary implants as per the training and experience of the surgeon. There is as yet no consensus in literature regarding whether to use short or long IM nails. Hemiarthroplasty may still find favour in cases with fracture comminution in elderly with severe osteoporosis or in cases with failed fixation of intertrochanteric fracture ${ }^{[11]}$. As far as possible fixation of IT fractures is to be attempted rather than a hemiarthroplasty. It seems that intertrochanteric fractures treated with PFN may achieve better functional results than treated with hemiarthroplasty in the short and middle term, however longer follow-up studies are needed to confirm it.

Limitations: limitations include small group and mid term follow up. The implant-related complications occur usually in the first year after operation in patients treated with PFNA, while increase with time in patients treated with hemiarthroplasty. To compare the implant-related complications of the two methods and functional assessment long term follow-up studies are needed.

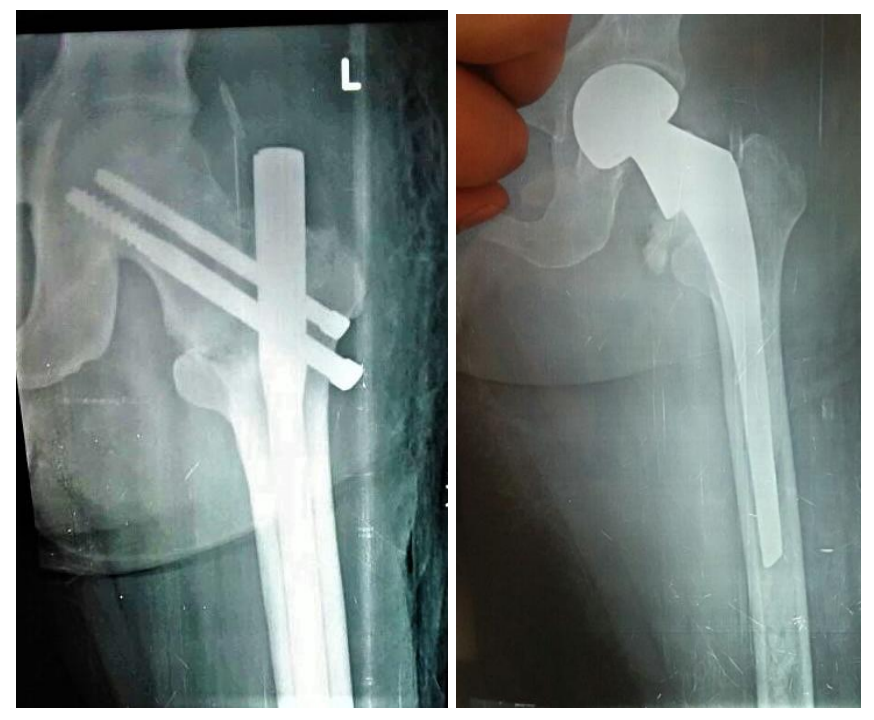

Fig 1: showing PFN and bipolar prosthesis used to manage intertrochanteric fractures.

\section{Conclusion}

In conclusion, our results shows that both PFN and cemented, bipolar hemiarthroplasty are beneficial techniques in treatment of intertrochanteric femoral fractures. Internal fixation may be more appropriate for elderly patients with poor general conditions due to shorter duration of operation, lesser surgical trauma and lower risk of reoperation with progressive improvement in Harris hip score. Postoperative medical complications are more in CBP group whereas postoperative orthopaedic complications are almost similar.

6. Acknowledgement: No financial support was received for this study

\section{Conflict of interest: None}

\section{Reference}

1. Colais P, Pinnarelli L, Fusco D, et al. The impact of a pay-for-performance system on timing to hip fracture surgery: experience from the Lazio Region (Italy). BMC Health Services Research. 2013; 13:39. 
2. Kannus P, Parkkari J, Sievonen H, Heinonen A, Vuori I, Jorvinen M. Epidemiology of hip fractures. Bone; 1996; 18:57S-63S.

3. Koval KJ, Zuckerman JD. Hip fractures are an increasingly important public health problem. Clin Orthop Relat Res, 1998; 348:2.

4. Ozkayın N, Okçu G, Aktuglu K. Intertrochanteric femur fractures in the elderly treated with either proximal femur nailing or hemiarthroplasty: a prospective randomised clinical study. Injury. 2015; 46(2):S3-8.

5. Liu Y, Tao R, Liu F, Wang Y, Zhou Z. Mid-term outcomes after intramedullary fixation of peritrochanteric femoral fractures using the new proximal femoral nail antirotation (PFNA) Injury. 2010; 41:810-817.

6. Sadic S, Custovic S, Jasarevic M, Fazlic M, Smajic N, Hrustic A. Proximal femoral nail in treatment of fractures of proximal femur. Med. Arch. 2014; 68:173-177.

7. Li M, Wu L, Liu Y, Wang C. Clinical evaluation of the Asian proximal femur intramedullary nail antirotation system (PFNA-II) for treatment of intertrochanteric fractures. J. Orthop. Surg. Res. 2014; 13:1-8.

8. Gardenbroek TJ, Segers MJ, Simmermacher RK, Hammacher ER. The proximal femur nail : an identifiable improvement in the treatment of unstable pertrochanteric fractures. J. Trauma. 2011; 71:169-174.

9. Harris WH. Traumatic arthritis of the hip after dislocation and acetabular fractures: treatment by mold arthroplasty. An end result study using a new method of result evaluation ; JBJS American. 1969; 51(4):737-55.

10. Sinno K, Sakr M, Girard J, Khatib H. The effectiveness of primary bipolar arthroplasty in treatment of unstable intertrochanteric fractures in elderly patients. N. Am. J. Med. Sci. 2010; 2:561-568.

11. Sancheti KhSancheti P, Shyam A, Patil S, Dhariwal Q, Joshi R. Primary hemiarthroplasty for unstable osteoporotic intertrochanteric fractures in the elderly: a retrospective case series. Indian J. Orthop. 2010; 44:428434.

12. Liang YT, Tang PF, Guo YZ, Tao S, Zhang Q, Liang XD. Clinical research of hemiprosthesis arthroplasty for the treatment of unstable intertrochanteric fractures in elderly patients. Zhonghua Yi Xue Za Zhi. 2005; 85:3260-3262.

13. Singh S, Shrivastava C, Kumar S. Hemi replacement arthroplasty for unstable inter-Trochanteric fractures of femur. J. Clin. Diagn. Res. 2014; 8(10):LC01-LC04.

14. Tang P, Hu F, Shen J, Zhang L, Zhang L. Proximal femoral nail antirotation versus hemiarthroplasty: a study for the treatment of intertrochanteric fractures. Injury. 2012; 43:876-881.

15. Shen J, Wang DL, Chen GX, Yang HL, Li L, Wei MX et al. Bipolar hemiarthroplasty compared with internal fixation for unstable intertrochanteric fractures in elderly patients. J Orthop Sci. 2012; 17:722-729

16. Pho RW, Nather A, Tong GO, Korku CT. Endoprosthetic replacement of unstable, comminuted intertrochanteric fracture of the femur in the elderly, osteoporotic patient. J. Trauma. 1981; 21:792-797.

17. Siwach R, Jain H, Singh R, Sangwa K. Role of hemiarthroplasty in intertrochanteric fractures in elderly osteoporotic patients: a case series. Eur. J. Orthop. Surg. Traumatol. 2012; 22:467-472.

18. Chu X, Liu F, Huang J, Chen L, Li J, Tong P. Good short-term outcome of arthroplasty with Wagner SL implants for unstable intertrochanteric osteoporotic fractures. J. Arthroplasty. 2014; 29:605-608.

19. Choy WS, Ahn JH, Ko JH, Kam BS, Lee DH. Cementless bipolar hemiarthroplasty for unstable intertrochanteric fractures in elderly patients. Clin. Orthop. Surg. 2010; 2:221-226.

20. Simmermacher RK, Ljungqvist J, Bail H, Hockertz T, Vochteloo AJ, Ochs U et al. The new proximal femoral nail antirotation (PFNA) in daily practice: results of a multicentre clinical study. Injury. 2008; 39:932-939.

21. Soucanye de Landevoisin E, Bertani A, Candoni P, Charpail C, Demortiere E. Proximal femoral nail antirotation (PFN-ATM) fixation of extra-capsular proximal femoral fractures in the elderly: retrospective study in 102 patients. Orthop. Traumatol. Surg. Res. 2012; 98:288-295. 